\title{
Avaliação da pós-graduação em Educação: questões, dilemas e algumas proposições
}

\author{
Luciano Mendes de Faria Filho ${ }^{1}$
}

\section{Resumo}

Este texto trata da avaliação da pós-graduação no Brasil, dando especial ênfase à área de Educação. O seu objetivo é contribuir para o debate sobre a prática avaliativa e sobre sua importância entre nós, no que se refere à formação de professores e pesquisadores e à produção científica nacional. Para isso, reúne argumentos sobre os temas estabelecidos historicamente como sendo os mais fundamentais a serem avaliados e, a respeito de cada um deles, discute certos fundamentos, buscando oferecer sugestões para sua avaliação. Ao final, ultrapassando a avaliação periódica da pós-graduação, sugere que é preciso que se estabeleça uma política científica para a área de educação que articule formação e produção de conhecimentos, dando, assim, sentido à própria avaliação, evitando que se converta na única política possível para a área.

Palavras-chave: Pesquisa educacional. Política de pesquisa. Formação de pesquisadores. Avaliação.

1 Faculdade de Educação/ UFMG. 


\title{
Post-graduation assessment in the field of education: questions, dilemmas and some propositions
}

\begin{abstract}
This text works with the post-graduation assessment in Brazil giving special emphasis to the field of education. Its aim is to contribute to the debate about the evaluation practice and its importance to professor and researcher training and the national scientific production. To do so, it joins arguments about the historically settled themes as the main ones to be evaluated as well as discuses each of them giving suggestions for their evaluation. At the end, beyond the periodic evaluation of post-graduate studies, it suggests the importance of the establishment of a scientific policy to the field of education, which links teachers training and knowledge production avoiding that the evaluation becomes the only possible policy for the field.
\end{abstract}

Keywords: Research on Education; Research policy; Researchers training; Assessment

Os últimos tempos não têm sido fáceis para a pós-graduação brasileira e, por consequência, para aqueles que diuturnamente se dedicam à formação e à pesquisa nesse nível de ensino. Às sucessivas trocas de ministros, que impactaram sobremaneira o conjunto das políticas educacionais no país, somaram-se as indefinições quanto à direção da CAPES e, no caso da área da Educação, as dificuldades de integração entre a Educação Básica e o Ensino Superior na agência, bem como a alteração do período de avaliação que, dos três anos tradicionais, passou para quatro, no meio do caminho. Não bastasse isso, vieram os profundos 
cortes de verbas em 2015 e, mais recentemente, o recolhimento, pela CAPES, dos recursos de bolsas consideradas "ociosas" pela agência, mesmo que essa ociosidade tenha sido veementemente negada pelos programas de pós-graduação.

No caso da área da Educação, vivemos ainda dificuldades adicionais advindas seja das políticas e das ações da CAPES - a dificuldade de a agência aceitar com tranquilidade os livros como um produto acadêmico de excelência e a demora em indicar a Coordenação da Área, por exemplo - seja da configuração da pesquisa e da pós-graduação na própria área - elevado número de programas, de pesquisadores e de alunos e a dificuldade de se estabilizar os critérios de avaliação, por exemplo.

Nesse momento, estamos chegando ao final do quarto ano do quadriênio que será avaliado, e é sensível na área certa apreensão quanto ao processo de avaliação e, consequentemente, aos rumos que tomará a pós-graduação em Educação no país. Tal apreensão é perfeitamente justificável, já que a avaliação dos programas tem impacto direto e imediato no financiamento dos alunos (bolsas) e de boa parte das atividades de formação desenvolvidas pelos mesmos. Essa relação direta entre a avaliação e o financiamento, que já é difícil de equacionar em momentos de normalidade econômica, torna-se mais crítica em tempos de crise financeira como os que estamos vivendo.

Objetivando contribuir com o debate sobre o processo de avaliação da pós-graduação na área de educação, reuni aqui uma série de textos publicados no jornal Pensar a Educação em Pauta. Os temas sobre os quais versaram os artigos foram: (a) a relação entre pesquisa e pós-graduação no Brasil; (b) a educação no sistema de pesquisa e de pós-graduação; (c) o financiamento da pesquisa e da pós-graduação; (d) os critérios de avaliação dos programas: instabilidade e indefinição; (e) avaliação dos programas x avaliação dos pesquisadores; (f) entre o produtivismo e a produção qualificada; (g) que internacionalização nos interessa?; (h) o impacto social dos programas.

Foi a partir dessa elaboração que fiz minha intervenção na $12^{\mathrm{a}}$ Reunião Científica Regional Sudeste da ANPED, ocorrida em julho de 2016, na UFES. A partir dos debates suscitados pela mesa redonda, elaborei, 
então, um último texto, que foi publicado originalmente no Blog do Pensar a Educação em Pauta, e que aqui trago como fechamento de minhas reflexões.

a) Pós-graduação e pesquisa no Brasil: as faces perversas de um projeto exitoso: há um consenso entre os especialistas em Educação de que a pós-graduação é a etapa de formação escolar que mais deu certo no Brasil. Apesar de deitar raízes nas experiências universitárias e dos institutos de pesquisas que são anteriores aos anos de 1960, o atual modelo de institucionalização da pesquisa e da formação de alto nível é profundamente devedor da reforma universitária de 1968 e do grande apoio dos governos militares à pós-graduação, com o intuito de formar um amplo sistema de ciência e de tecnologia no país.

Dessa forma, no Brasil, contrariamente ao que ocorreu em quase todos os países ocidentais com larga tradição de pesquisa, a pósgraduação não significou simplesmente a organização da formação de pesquisadores em outro patamar institucional, mas a própria organização da pesquisa cientifica no país. Disso resultou um sistema científico-acadêmico profundamente depende dessa forma peculiar de formação de pesquisadores, que é a pós-graduação. E, o que não é menos importante, resultou num modo peculiar de organizar a pesquisa, que é muito devedor dos modelos, das exigências, dos rituais e dos modos de consagração próprios ao campo acadêmico-científico.

Assim, a pesquisa foi expandida e, ao mesmo tempo, constrangida pela elaboração e apresentação pública de dissertações, teses, artigos, relatórios e livros que, em boa parte, estavam mais voltados para a consagração acadêmica e intelectual do que propriamente com a inovação científica e tecnológica e com o desenvolvimento social e cultural brasileiros. Ressalte-se ainda que a demanda e a pressão do próprio sistema universitário, que se erigia por quadros titulados em nível de doutorado, fizeram com que o modelo fosse forçado a produzir mais e mais titulados que, mais do que desenvolver pesquisas de ponta, estavam mobilizados pelas oportunidades de inserção institucional e pelos avanços em suas carreiras universitárias proporcionados por essa 
formação.

Também as agências de fomento, de avaliação e de regulação que se estruturavam, operadas quase sempre pelos pesquisadores das áreas que mais rapidamente se institucionalizaram dentro desse novo modelo, foram mobilizadas para o fortalecimento dessa lógica que presidiu a organização do sistema, também fazendo com que o financiamento estivesse cada vez mais dependente da performance dos pesquisadores, dentro dos critérios de consagração acadêmica e da avaliação dos programas de pós-graduação.

Há, no entanto, hoje, grande consenso de que o modelo precisa ser posto de ponta-cabeça. Ele dá sinal de disfuncionalidade em todas as áreas. $\mathrm{O}$ atual regramento da pós-graduação torna difícil a pesquisa inovadora e inviabiliza arranjos acadêmicos e institucionais que deem suporte ao desenvolvimento científico contemporâneo. Estamos, hoje, tentando responder a desafios novos em todas as áreas do conhecimento com base numa estrutura antiga, que mais engessa do que promove a pesquisa.

Construída para formar pesquisadores e professores universitários, a pós-graduação atual não está à altura e nem é suficiente para responder às novas exigências de formação postas pelo desenvolvimento social, econômico, político e cultural do mundo contemporâneo. Esse modelo de formação de quadros para o sistema universitário, que se mostrou de grande sucesso nas décadas iniciais de sua implantação, veio sendo continuamente engessado, padronizado e constrangido por um conjunto de regras que, ao fim e ao cabo, colocam os programas e os pesquisadores subservientes aos resultados demandados pelas avaliações, pois dessas dependem diretamente o financiamento necessário ao seu funcionamento.

Nesse sentido, se queremos fazer pesquisa de ponta e se queremos responder às novas exigências da formação de profissionais de alto nível, é preciso libertar a pesquisa da pós-graduação! Isto significa dizer que a pesquisa e a formação não podem ficar constrangidas apenas pelos modelos de consagração acadêmicos. Mas não apenas isso: significa dizer também que algumas regras importantes para a organização 
da formação no âmbito dos programas de pós-graduação (tempo de titulação, o aprendizado dos modelos consagrados de exposição etc.) são, muitas vezes, prejudiciais à realização da pesquisa de ponta em vários campos do conhecimento.

A criatividade, a ousadia e a experimentação necessárias à produção do conhecimento científico de ponta exige, por suposto, sólida formação teórica e metodológica no campo em que pesquisador se insere. E a pósgraduação pode contribuir para isso. No entanto, quando o modelo e as estruturas de formação são erigidos como lócus fundamental da pesquisa, e quando as regras de formação se impõem à pesquisa, o resultado pode até ser o aumento do número de titulados, mas nada garante que de tal pesquisa resultará um conhecimento mais denso e inovador.

Repactuar a relação entre a pesquisa e a pós-graduação no sistema de ciência e tecnologia poderia ser também uma forma de refundar nossas universidades, hoje amplamente capturadas e dirigidas pela e para a pósgraduação, em detrimento da produção de conhecimento que ocorre fora desses espaços, da graduação, da extensão e da própria administração universitárias. De nada adiantará falarmos de novas (ou não tão novas assim) exigências da/na produção de conhecimento, como a inter ou transdisciplinaridade, da necessidade de aproximação da pesquisa com o mundo da produção ou das políticas públicas, ou mesmo da necessidade de um compromisso do pesquisador com a comunicação pública de sua pesquisa, ou da universidade com a escola básica, se não mudarmos a estrutura que preside as nossas instituições.

b) A Educação na pós-graduação e no sistema de C\&TI brasileiros: o CNPq publicou, em meados de 2015, os resultados do Censo dos Grupos de Pesquisa, realizado em 2014. É um conjunto de dados muito importante e de grande interesse para toda a comunidade de pesquisa do país. Como era de se esperar, os dados revelam que houve aumento substantivo do número de pesquisadores inscritos nos grupos de pesquisa em praticamente todas as áreas.

No caso da Educação, especificamente, o número de pesquisadores inscritos nos Grupos de Pesquisa subiu de pouco mais de $14 \mathrm{mil}$ pesquisadores, em 2010, para mais de 22 mil, em 2014. A área de 
Educação confirma, assim, ser a maior área do sistema nacional de ciência e tecnologia. Só para se ter uma ideia, a segunda maior área, de acordo com os dados do Censo, é a área de Medicina, com 10655 pesquisadores, ou seja, com menos da metade do número de pesquisadores inscritos em Grupos de Pesquisa da área de Educação.

Mas os dados trazem informações tão ou mais relevantes do que essas. Eles permitem, por exemplo, verificar quais as áreas têm maior ou menor poder de atração de pesquisadores estrangeiros. Nesse quesito, a capacidade de atração da área de Educação é muito baixa, em relação a outras. A Física, por exemplo, conta com 450 pesquisadores estrangeiros, o que corresponde a quase $10 \%$ dos pesquisadores inscritos nos Grupos de Pesquisa da área. Do mesmo modo, a Antropologia brasileira demonstra ter boa capacidade de atrair quadros de outras nacionalidades: os seus 171 pesquisadores estrangeiros correspondem a 6\% do conjunto daqueles inscritos em seus Grupos de Pesquisa. Já na área de Educação, os 381 pesquisadores estrangeiros inscritos nos seus Grupos correspondem a menos de $2 \%$ do total de pesquisadores da área.

\section{Pesquisadores estrangeiros por área}

\begin{tabular}{|l|l|l|l|}
\hline Área & Pesquisadores & Estrang. & E/P \\
\hline Educação & 22272 & 381 & 1,7 \\
\hline Física & 4729 & 450 & 9,5 \\
\hline Antropologia & 2850 & 171 & 6,0 \\
\hline
\end{tabular}

Fonte: Censo de Gurupos de Pesquisa - CNPq/2014

\section{Bosla de Produtividade em pesquisa por área}

\begin{tabular}{|l|l|l|l|}
\hline Área & Pesquisadores & Estrang. & P/B \\
\hline Educação & 22272 & 399 & 55 \\
\hline Física & 4729 & 941 & 5 \\
\hline Antropologia & 2850 & 151 & 18 \\
\hline
\end{tabular}

Fonte: Censo de Gurupos de Pesquisa - CNPq/2014 
Em 2015, segundo dados do CNPq, havia 14.544 bolsas de produtividade em pesquisa no sistema. Observando os dados do quadro acima, percebemos que, enquanto na Educação há uma bolsa para cada 55 pesquisadores inscritos nos grupos de pesquisa, na Física há uma bolsa para cada 5, e na Antropologia, uma bolsa para cada 18. Mesmo considerando-se que o número de doutores, os únicos que podem disputar a bolsa de produtividade em pesquisa, possa ser relativamente maior em relação ao número de pesquisadores inscritos nos Grupos de Pesquisa nas áreas de Física e de Antropologia do que na Educação - ou seja, pode ser que, na área de Educação, mais não doutores se inscrevam ou sejam inscritos como pesquisadores - estamos aqui diante de uma desigualdade gritante em relação ao número de bolsas de produtividade nas três áreas, com clara desvantagem para a Educação.

Entender as razões históricas, sociais, culturais e políticas que presidiram a constituição e a diferenciada presença das comunidades de pesquisa no sistema de C\&TI no Brasil, bem como a transformação dessas diferenças em desigualdades de acesso ao financiamento, é uma tarefa que não nos cabe aqui. No entanto, não podemos desconsiderar a necessidade de nos debruçarmos sobre esse conjunto de dados e, na medida do possível, transformarmos nossas análises em proposições de políticas que visem corrigir as distorções existentes e evitar que novas distorções venham a ser produzidas.

Boa parte dos pesquisadores da área de Educação do CNPq está vinculada, na CAPES, aos cursos de Pós-graduação das áreas de Educação e de Ensino. A tabela a seguir informa o número de cursos de Mestrado (M), Doutorado (D) e Mestrado Profissional (F) das duas áreas.

\begin{tabular}{|l|c|c|c|c|}
\hline \multicolumn{5}{|c|}{ Totais de cursos de pós-graduação } \\
\hline & $\mathrm{M}$ & $\mathrm{D}$ & $\mathrm{F}$ & Total \\
\hline Área educação & 128 & 74 & 42 & 244 \\
\hline Área ensino & 58 & 31 & 74 & 163 \\
\hline Total & 186 & 105 & 116 & 407 \\
\hline
\end{tabular}

Fonte: CAPES

Somados, o número de cursos das duas áreas totaliza 407. Tomada 
isoladamente, a área de Educação, pois é da avaliação dos cursos dessa área que aqui se fala, reúne 244 cursos, número inferior apenas ao total de cursos da Área Interdisciplinar, com 433 cursos, e das Ciências Agrárias I, com 369 cursos.

Segundo o Qualis Periódicos da CAPES, os professores e alunos vinculados aos cursos de Pós-graduação em Educação publicaram em mais de 1300 periódicos nacionais e internacionais nos últimos anos. Essa dispersão, no entanto, não é característica apenas da área de Educação. Áreas maiores, como a Agrárias I, também a apresenta, tendo seus pesquisadores e alunos publicado em mais de 1600 periódicos, bem como áreas mais consolidadas no campo acadêmico científico, como a Física, em que alunos e professores de seus 106 cursos publicaram em mais de 700 periódicos.

Além da publicação em periódicos, há que considerar ainda a publicação de livros. Segundo o Relatório da Avaliação do Triênio 2010-2012, a área produziu, em média, mais de 1500 livros por ano. E a tendência é de esse número aumentar!

Esse conjunto de informações, apesar de pequeno, permite-nos aquilatar a presença da área da Educação, em termos quantitativos, na Pós-graduação e no sistema de C\&TI brasileiro; ao mesmo tempo, interrogar sobre a capacidade de a área interferir nos rumos das políticas para a pós-graduação e para a pesquisa, assim como sobre a participação dos Programas de Pós-graduação no conjunto do fomento à pesquisa e da pós-graduação estabelecido no país.

No que se refere aos rumos das políticas, é sensível que as ciências humanas e sociais como um todo têm demonstrado baixa capacidade de interferir profundamente em sua elaboração, e mesmo em suas implementação e avaliação. Em boa parte, nossas áreas se mantêm na periferia dos postos de decisão e de implementação das políticas, seja porque vêm sendo ocupados historicamente por aquelas áreas que institucionalizaram o sistema, seja porque as ciências humanas e sociais não são consideradas prioritárias e relevantes nas políticas definidas e operacionalizadas pelos principais órgãos dos sistemas de pós-graduação e de C\&TI. 
Há, também, certa dificuldade de as "comunidades científicas" das ciências humanas e sociais, aí incluída a Educação, seja por meio dos Programas, seja por meio de suas instituições científicas, articularemse na defesa de causas que lhes afetam igualmente. Isso, aliado à baixa presença na Sociedade Brasileira para o Progresso da Ciência e na Academia Brasileira de Ciência, duas instituições fortes nas definições das políticas e das direções dos principais órgãos de fomento e de avaliação do sistema, acaba por reforçar a situação marginal dessas áreas.

No caso da Educação, não podemos nos esquecer de que os Programas, os pesquisadores e os alunos de pós-graduação estão também representados, política e academicamente, por mais de duas dezenas de instituições científicas. A crescente especialização da pesquisa e dos pesquisadores, aliada à necessidade de buscar visibilidade pública e acadêmica para a pesquisa realizada, levou os pesquisadores e os alunos de um número significativo de subáreas da Educação a se institucionalizarem em instituições científicas também especializadas que, não poucas vezes, concorrem entre si para representar publicamente a área da Educação. Há que se perguntar, a esse respeito, até que ponto não se repetiria na própria área da Educação aquilo que se observa, conforme acima descrito, na grande área de Ciências Humanas e Sociais.

É evidente que, devido à enorme autonomia da comunidade acadêmica e científica brasileira na definição dos rumos e das prioridades das políticas de C\&TI no Brasil, que a presença periférica das Ciências Humanas e Sociais nas definições de tais políticas e nas direções dos órgãos de fomento e de avaliação tende a levar a um financiamento bastante inferior, relativamente à sua presença quantitativa no sistema. O tema do financiamento da pesquisa e da pós-graduação em Educação é, pois, o objeto de reflexão do próximo tópico.

c) Financiamento à pesquisa em educação no Brasil: é impossível saber ao certo qual o montante de recursos aplicado no financiamento à pesquisa realizada pela área de Educação no país. Isso ocorre devido a vários fatores. Em primeiro lugar, como já se abordou anteriormente, a área de Educação da CAPES não tem relação direta com a área de mesmo nome no CNPq. Neste órgão, a área de Educação abrange, além 
da área de Educação da CAPES, a área de Ensino. Em segundo lugar, boa parte do financiamento à pesquisa ocorre via bolsas de formação de novos pesquisadores - Iniciação Científica, Mestrado e Doutorado - cujo montante é praticamente impossível de se precisar. Em terceiro lugar, porque, sobretudo no âmbito do MEC, há variadas formas de financiamento à pesquisa, seja por meio de editais, seja por meio de chamadas públicas às universidades, sobre as quais se tem muito poucas informações acessíveis no que se refere ao montante financiado. Não se pode esquecer, ainda, de que, saindo do âmbito Federal, há o financiamento realizado pelas Fundações de Amparo à Pesquisa dos diversos estados e, o que não é menos importante, a encomenda de pesquisas feiras pelas Secretarias de Estado da Educação diretamente às universidades e aos centros de pesquisa.

Observa-se que, além da existência de um conjunto de modalidades de financiamento - de forma direta, por meio do fomento à pesquisa, e, de forma indireta, por meio da formação de novos pesquisadores - é preciso se considerar que nem toda a pesquisa sobre Educação ocorre nos departamentos, programas ou grupos que se autoidentificam como sendo dessa área. Sabemos que há muita pesquisa sobre Educação sendo realizada, por exemplo, por grupos da área de Economia e Saúde. Dessa forma, o certo é que há uma razoável soma de recursos aplicados na produção de conhecimentos sobre Educação no Brasil, ainda que nem sempre financiando pesquisas realizadas pela nossa área.

No âmbito do MEC/CAPES, boa parte dos recursos é direcionada aos Programas de Pós-graduação e é aplicada, sobretudo, no custeio de bolsas de mestrandos e doutorandos. As regras determinam a aplicação compulsória de um mínimo de $70 \%$ dos recursos em bolsas, mas, na área de Educação, o mais comum é que os programas apliquem muito mais do que isso, configurando uma situação em que, mesmo quando recebem verbas da CAPES, essa verba não financia diretamente a pesquisa dos professores, e sim a formação de novos pesquisadores. Talvez esse seja um dos motivos pelos quais a pesquisa está a depender, no Brasil, cada vez mais, dos mestrandos e, sobretudo, dos doutorandos. No que se refere especificamente ao montante de recursos repassado pela CAPES 
aos Programas da Área de Educação, essa é uma informação que não foi encontrada no site da CAPES.

Ainda no âmbito do MEC/CAPES, não se pode deixar de mencionar os vários programas e os inúmeros editais que financiam a pesquisa em Educação. Praticamente todas as Diretorias do MEC, e também a área de Educação Básica da CAPES, publicam com certa regularidade editais e chamadas públicas para o financiamento de projetos dentro de escopos temáticos mais ou menos limitados. Apenas um desses programas, o dos Observatórios da Educação, operado, em conjunto, pela CAPES e pelo INEP, financia atualmente 90 projetos. Na última chamada, de 2012, era possível apresentar projetos locais no valor anual de até $\mathrm{R} \$ 232.480,00$, e projetos em rede no valor anual de até $\mathrm{R} \$ 697.440,00$. Infelizmente, o edital não tornou público o valor total a ser financiado, e não encontramos informação precisa sobre o que, de fato, foi alocado nos 90 projetos aprovados.

No caso do MCTI/CNPq, o financiamento é dirigido tanto para a formação de novos pesquisadores - IC, Mestrado e Doutorado - quanto para o custeio da pesquisa. É bem verdade que, apesar de ser uma das maiores áreas do sistema de C\&TI e de se relacionar diretamente com o maior e mais complexo serviço público brasileiro - os sistemas públicos de Educação, em seus variados níveis e modalidades - os pesquisadores da área de Educação não participam das modalidades mais nobres e de maiores recursos financeiros existentes no sistema: os Institutos Nacionais de Ciência e Tecnologia (INCTs) e os Programas de Apoio a Núcleos de Excelência (Pronex), ambos operados em conjunto pelo CNPq e pelas FAPs. O único INCT que se dedica especialmente à pesquisa em Educação é o Instituto Nacional de Ciência e Tecnologia de Educação, Desenvolvimento Econômico e Inserção Social, da Fundação Getúlio Vargas, no Rio de Janeiro.

No caso das bolsas de formação, as de IC, em sua maior parte, são distribuídas às universidades, via apresentação de propostas institucionais, e são elas as responsáveis por sua destinação aos pesquisadores. No caso das bolsas de mestrado e doutorado, é possível apresentar alguns números. Em 2015, o investimento do CNPq na área 
de Educação aparece como na tabela a seguir:

Número de bolsas e de investimentos em bolsas no país, com "ano" igual a "2015", com "área de conhecimento" igual a "Educação", agrupado(a) por "Modalidade"

\begin{tabular}{|l|l|l|}
\hline Modalidade & Número & Total (R\$) \\
\hline Iniciação Científica/PIBIC & 987,1 & 4.761 .600 \\
\hline Iniciação Científica Júnio & 597,9 & 718.000 \\
\hline Produtividade em Pesquisa & 386,6 & 7.768 .700 \\
\hline Mestrado & 280,9 & 5.347 .962 \\
\hline Apoio Técnico em Extensão no País & 261,2 & 1.605 .350 \\
\hline Doutorado & 204,6 & 6.689 .954 \\
\hline Iniciação Tecnológica Industrial & 165,1 & 559.639 \\
\hline Extensão no País & 124,1 & 2.830 .801 \\
\hline Iniciação Científica & 86,8 & 424.000 \\
\hline Apoio Técnico à pesquisa & 82,7 & 522.050 \\
\hline Desenvolvimento Tecnológico Industrial & 54,2 & 1.129 .061 \\
\hline Iniciação Tecnológica/PIBITI & 52,5 & 252.400 \\
\hline Pós-Doutorado Júnio & 27,8 & 1.544 .680 \\
\hline Iniciação ao Extensionismo & 17,1 & 74.160 \\
\hline Fixação de Recurso Humano & 13,5 & 315.700 \\
\hline Desenvolvimento & 12,3 & 728.000 \\
\hline Apoio à Difusão do Conhecimento & 6,4 & 35.984 \\
\hline Pós-Doutorado Sênior & 5,8 & 370.150 \\
\hline
\end{tabular}

Fonte: $\mathrm{CNPq}$

Percebe-se, pela tabela, que o CNPq gastou, na área de Educação, com bolsas, quase 36 milhões de reais. Destes, menos de 8 milhões foram destinados diretamente aos pesquisadores na forma de bolsas de produtividade em pesquisa e taxa de bancada (Grant). 
No âmbito do Edital Universal de 2014, 571 propostas demandaram quase 24 milhões de reais, das quais foram atendidas 204, com o valor de pouco mais de 6,5 milhões de reais. Já no Edital de Ciências Humanas do mesmo ano, foram submetidas 225 propostas, com demanda total de R $\$$ $5.518 .502,89$. A área de Educação recebeu a dotação de R $\$ 1.373 .489,00$, de um montante de R \$ 8.000.000,00 distribuídos pelo Edital, ou seja, 17,2\%.

No caso do fomento à pesquisa, não foi possível ainda conseguir dados financeiros precisos, mas, segundo informações encontradas no site do CNPq (Mapa de Investimento), a concentração do financiamento à pesquisa é maior ainda do que aquela observada no caso das bolsas de produtividade: apenas 6 instituições, todas de São Paulo e de Minas Gerais, concentravam mais de $50 \%$ dos projetos financiados, na área, pelo órgão.

Nessas condições antes demonstradas, subordinar o financiamento dos Programas de Pós-graduação às notas por eles obtidas na avaliação é uma maneira cabal de se aumentarem as desigualdades inter e intrarregionais. Os programas funcionam em condições de financiamento muito desiguais no conjunto do país, e, se isso não for levado em conta, a avaliação nada mais será do que uma chancela à desigualdade já instalada no sistema; mais do que isso, uma forma de sua reprodução e ampliação.

O problema, pode-se argumentar com certa razão, é que boa parte dessas regras independe da área e mesmo da Comissão de Avaliação de Área e do Comitê de Assessoramento do CNPq. No entanto, há que se buscar mecanismos que identifiquem tais desigualdades no acesso aos recursos financeiros e que os matizem no processo de avaliação. O estabelecimento de critérios que primem pela análise da qualidade da formação e da produção, assim como pela consideração do impacto regional dos programas, pode ser uma boa, ainda que insuficiente, saída. É disso que trataremos a seguir.

d) Os critérios de avaliação dos programas - instabilidade e indefinição: no Brasil, é difícil estabelecer com segurança quais são os critérios para se avaliar a excelência dos Programas de Pós-graduação em Educação, seja em sua face de formação de novos pesquisadores e professores, seja em relação aos resultados da pesquisa realizada. 
Mesmo os pesquisadores (e avaliadores) mais experientes demonstram ter dúvidas a esse respeito, e os critérios mobilizados estão sujeitos a razoáveis controvérsia e desconfiança. Neste momento mesmo, estamos caminhando para o final do quarto ano do quadriênio que será avaliado, e os critérios de avaliação da pós-graduação ainda não foram estabelecidos publicamente pela Comissão de Área. É como se estivéssemos definindo as regras do jogo após o seu término!

As razões dessa nossa dificuldade podem ser buscadas em diferentes dimensões do campo educacional. Há, por um lado, o fato de que a institucionalização da pesquisa ocorre muito recentemente e pelas mãos da própria pós-graduação, como já se disse antes. A ausência de uma tradição de pesquisa autônoma em relação à pós-graduação nos fez crer que avaliar a pós-graduação é avaliar a pesquisa. Interligado a isso está, sem dúvida, a falta de uma clara distinção entre a pós-graduação como lócus de formação de pesquisadores e professores e como lócus de realização da pesquisa. Disso resulta, muitas vezes, a confusão de querermos fazer o contrário do que se disse acima: a crença de que avaliar os resultados da pesquisa é avaliar a pós-graduação.

Há ainda outra razão para a nossa particular dificuldade de dar estabilidade aos critérios para a avaliação da pós-graduação: o fato de que a área não tem autonomia para definir os seus próprios critérios. Essa dimensão, das mais importantes, está relacionada à forma como se organizou o sistema CAPES, com a proeminência daquelas áreas que mais acumularam capital científico-acadêmico e, portanto, poder na definição das regras do jogo. Como a avaliação está umbilicalmente relacionada ao financiamento, controlar as formas de avaliar é também controlar o fluxo de financiamento dentro do sistema. Mas há ainda a compreensão de que as áreas melhor estabelecidas no campo acadêmico podem e devem tutelar as demais áreas, notadamente das Ciências Humanas e Sociais, de tal forma que os critérios de cientificidade e de legitimidade daquelas possam servir de parâmetros para a realização de "boas pesquisas" por essas últimas.

Dessas razões resulta parte significativa de nossas dificuldades em definir e em dar estabilidade aos nossos critérios de avaliação. 
Mas, creio, há outro conjunto de fatores internos à área que nos cria constrangimentos, às vezes impossíveis de serem removidos, na definição e na estabilização dos critérios.

Como um objeto de investigação e uma prática social situados no terreno da cultura, e que, portanto, envolve todas as dimensões do mundo social, a Educação é marcadamente polissêmica. Parte desta polissemia marca, obviamente, as próprias noções de qualidade, ou de excelência, mobilizadas pelos distintos atores que disputam o campo educacional. Não raramente, por isso, na avaliação da pós-graduação, os sujeitos estabelecem a legitimidade de suas posições não a partir do campo acadêmico-científico, mas a partir das razões políticas e ideológicas.

A esse fator soma-se o fato de sermos uma área muito grande, diversificada e de baixa institucionalização acadêmico-científica. Somos, hoje, como já se disse, quase 250 cursos; temos fronteiras ou porosidade com praticamente todas as demais áreas do sistema. Isso que faz com que tenhamos pesquisadores e alunos que foram formados nas mais diversas culturas acadêmico-científicas (inclusive em nenhuma cultura acadêmico-científica!), e boa parte de nossas estruturas funciona de forma quase amadora, para dizer o mínimo.

Para dar um exemplo: a publicação em periódicos científicos é um dos principais critérios mobilizados, hoje, para avaliar a excelência dos Programas de Pós-graduação, e, talvez por isso, somos, seguramente, a área do Sistema de Pós-graduação que conta com o maior número de periódicos científicos nacionais. No entanto, todo o complexo sistema de publicação de periódicos funciona de forma extremamente amadora e, portanto, sujeito a vicissitudes institucionais e pessoais das mais elementares. A sorte de nossos periódicos está sempre a depender da mudança de Direção de um Centro ou Faculdade, ou da continuidade ou não da ação de um(a) “dedicado(a)" editor(a)! Isso, evidentemente, sem dizer das contínuas mudanças e interrupções que marcam a política de financiamento dos periódicos pelas agências de fomento e pelas nossas instituições.

No entanto, a par disso tudo, é preciso perguntar se seria possível 
definir e estabilizar os critérios básicos de avaliação dos Programas de Pós-graduação. E, se sim, em que direção deveríamos caminhar.

Em primeiro lugar, creio que o fundamento primeiro de qualquer critério de avaliação é o fato de que ele deve ser conhecido por todos os participantes antes do início do jogo. Não é possível levar muito a sério uma avaliação cujos critérios mobilizados pelos avaliadores são definidos a posteriori, depois do jogo terminado. Se eu não sabia como seria julgado, como posso ser cobrado por algo que fiz ou que deixei de fazer? E, convenhamos, não há razão para que não saibamos de antemão quais serão os critérios básicos que serão utilizados na avaliação de nossos programas. Mesmo as grandes controvérsias que marcam a área, como se disse, não são justificativas suficientes: como a avaliação é, agora, quadrienal, de quatro em quatro anos, as controvérsias poderiam ser reapresentadas, discutidas e, se fosse o caso, os critérios poderiam mudar.

Nesse sentido, uma das primeiras e mais importantes iniciativas para tornar a avaliação mais legítima e transparente para todos seria a definição clara dos critérios antes do início do período que será avaliado. Não precisaria nem ser em relação a todos os critérios, mas, pelo menos, àqueles basilares, tais como os referentes à avaliação da produção científica (o Qualis Periódico e os critérios de avaliação dos livros, por exemplo) e aqueles também fundamentais, referentes à avaliação da formação ofertada pelos programas a seus alunos. Não há razão para que não possamos acordar que o Qualis estabelecido no início do primeiro ano do quadriênio valerá para os quatro anos, e que somente será alterado, no percurso, devido à inclusão de novos periódicos. A alegada razão de que os periódicos mudam de "qualidade" ao longo do quadriênio não é nem um pouco convincente diante do prejuízo trazido pela incerteza da indefinição dos critérios.

Nesse último aspecto, penso que já está mais do que na hora de insurgirmos coletivamente contra critérios de avaliação que, notoriamente, não servem nem para avaliar a qualidade da formação e, muito menos, a qualidade da produção, mas que têm razoável peso na avaliação dos programas. Um deles é, certamente, o prazo de conclusão do curso. Não há razão intrínseca à pós-graduação para dizer que 
alguém tem que defender uma dissertação em 24 meses, ou uma tese em 48 meses. Talvez por isso mesmo em praticamente nenhum outro país haja critério de tempo de conclusão tão rigidamente demarcado como no Brasil. As duas únicas razões que sustentam a permanência desse critério é a (in)capacidade de financiamento do sistema, por meio das bolsas, e a necessidade de se acelerar a consecução das metas de formação de mestres e doutores estabelecidas pelas nossas agências de fomento e de avaliação. Do ponto de vista dos tempos lógicos da pesquisa e da formação, e, mesmo, do papel social dos nossos programas, o tempo de conclusão rigidamente estabelecido pode ser absolutamente contraproducente.

Do mesmo modo, penso que não podemos confundir a qualidade da formação com a qualidade da pesquisa, esta aferida por meio da avaliação das publicações. Se a pós-graduação é, primeiramente, lócus da formação de novos pesquisadores e de professores, e, secundariamente, lócus da pesquisa de ponta, é preciso que desenvolvamos critérios para avaliar a formação ofertada por esses programas. Aferir apenas a "proposta do curso" e as "ofertas de disciplina" é muito pouco. Uma das formas de fazer isso seria considerar que a dissertação e a tese, mais do que o artigo publicado em revista, o trabalho completo em anais de evento ou o capítulo, objetivam a qualidade do programa tal como foi apreendida pelos alunos. Nesse caso, seria necessário avaliar também as dissertações e teses defendidas.

Finalmente, uma questão de grande relevância é a definição dos critérios de classificação dos programas como sendo de excelência internacional, ou seja, com as notas 6 e 7 . Dado que os programas de notas 6 e 7 ganham grande notoriedade e participam de forma particular de financiamento no conjunto do sistema, há grande interesse e necessidade de que os critérios de "acesso" a essa classificação sejam conhecidos por todos. E, dado o fato de que é preciso razoável nível de planejamento e largo tempo para que um Programa possa chegar e se estabilizar nesse nível, é de grande importância que os critérios para isso sejam claros e que gozem de razoável estabilidade. Não é desejável, por exemplo, que tais critérios mudem radicalmente a cada período de avaliação. Se 
assim o é, aqui, ainda mais do que na avaliação geral da pós-graduação, é imperioso que sejam conhecidos com grande antecedência.

Mesmo que haja um conjunto de outros expressivos elementos envolvidos na definição dos critérios de avaliação dos Programas de Pós-graduação, é preciso que o texto termine. E, ao fazê-lo, gostaria de retomar uma dimensão pouco mobilizada no âmbito da discussão do tema: como realizar uma avaliação que seja também mais justa do ponto de vista educacional, social e, mesmo, financeira? Essa questão nos remete à difícil tarefa de produzir e de mobilizar critérios de avaliação que apreendam o Programa como um todo, e não somente como reunião ou somatório de pesquisadores e alunos particulares. Não pode ser justa, por exemplo, uma avaliação que não considere as enormes desigualdades econômicas e financeiras que marcam nossas regiões e, mesmo, os estados da federação. É a respeito dessas e de outras questões que vamos discutir no próximo tópico, ao defender a necessidade de estabelecermos critérios que distingam claramente a avaliação dos programas daquelas avaliações que incidem sobre os pesquisadores individuais.

e) Avaliação dos programas x avaliação dos pesquisadores: é sabido por todos que os Programas de Pós-graduação foram organizados no país como forma de institucionalizar a pesquisa e de estruturar a formação de professores pesquisadores para o ensino superior brasileiro, além de para reunir investigadores que até então vinham realizando suas pesquisas, ainda que incipientes, de forma individual ou pouco articulada. Reunilos em programas, dar-lhes feição de grupo, financiar a formação e a pesquisa aí realizadas foram as pedras de toque da invenção da nossa pós-graduação e do fortalecimento da CAPES.

No entanto, isso, aparentemente, não foi combinado com o outro grande órgão de fomento do sistema: o CNPq. Tanto é verdade que, até o início da década de 1990, boa parte dos investimentos do CNPq era feita individualmente, em cada pesquisador. Baldados os esforços de lá para cá, a não ser as grandes estruturas de pesquisa (Proex e INCT, sobretudo), o CNPq ainda prima por uma atuação dirigida ao pesquisador individualmente, ainda que este, hoje, cada vez mais, esteja trabalhando em grupo. O Projeto Integrado de Pesquisa, uma 
modalidade de financiamento a grupos ensaiada nos anos de 1990, não logrou continuidade nas políticas do órgão.

O que vemos é que não se processou, ainda, uma síntese entre essas duas dimensões na avaliação da pós-graduação: o que deveria ser uma avaliação do trabalho coletivamente realizado acaba, em boa parte das vezes e em algumas das dimensões mais fundamentais, sendo avaliação dos pesquisadores individualmente considerados.

Uma avaliação do conjunto de cada Programa deveria matizar o máximo possível aqueles critérios ou quesitos que incidem sobre cada docente. Isto porque, todos nós sabemos, fazer um Programa de ótima qualidade implica a reunião e a conjunção de vários fatores institucionais que raramente são de responsabilidades de indivíduos. De outra parte, e mais importante de tudo, para se fazer um ótimo Programa, é preciso reunir pessoas, pesquisadores e alunos com sensibilidade e competências diversas, as quais devem se complementar para que o Programa funcione.

O que ocorre hoje é que, em boa parte, o processo de avaliação parece considerar que a qualidade do Programa é a soma das qualidades das pessoas que o compõem, e não a interpelação e a interdependência entre elas. Nossos critérios acabam por desconsiderar aquilo que todos sabemos existir: há docentes que são melhores orientadores que pesquisadores; há ótimos pesquisadores que são péssimos professores; temos ótimos extensionistas que não querem se inserir no campo acadêmico; e há poucos de nós competentes e dispostos a assumirem os postos de gestão, sobretudo nas instituições públicas. Um ótimo programa se faz, necessariamente, pela conjugação desses esforços, dessas sensibilidades e dessas competências. Se assim o é, por que não desenhar critérios que levem em conta o funcionamento desse conjunto, e não, como é hoje, sobretudo a ação individual de cada um no Programa?

Nossos critérios, por outro lado, obrigam os programas a desconsiderarem a específica e criativa contribuição de cada um, para estabelecer patamares mínimos de rendimento de cada docente. Todo mundo tem que dar aula! Todo mundo tem que orientar tantos alunos! Todo mundo tem que publicar tantos "produtos"! Todo mundo tem que ter no mínimo/máximo tantos projetos! Todo mundo tem... Mas será que 
isso mede realmente a qualidade de um Programa em suas dimensões mais fundamentais?

Por exemplo, como avaliarmos, hoje, a qualidade da formação oferecida pelos programas aos alunos que os frequentam? Como sabemos se os egressos de tal ou qual Programa são melhores professores, pesquisadores ou extensionistas do que os de outro? Simplesmente não sabemos!

Imaginamos, e passamos a concordar, que um docente pode até publicar muito, mas cada um tem que publicar um mínimo de dois produtos qualificados por ano. Abaixo disso, a qualidade do Programa se veria comprometida. Mas, digamos a verdade, não há evidência de que isso seja verdade. Assim como não há evidência de que se, num determinado Programa, deixarmos alguém mais livre para publicar, outros mais livres para dar aula e outros, ainda, mais livres para fazerem a gestão ou a extensão, que tal Programa será pior do que outros em que os professores sejam medianamente envolvidos em tudo.

Na verdade, o que conseguimos realmente avaliar, na gramática atual da avaliação da pós-graduação, é aquilo que pode ser mensurado, que pode ser transformado em número. Muitos podem dizer, e com certa razão, que dado o tamanho do sistema, não há mesmo outra maneira de se proceder. Mas, se isso é um fato, vamos transformá-lo explicitamente em único critério e deixarmos de fazer exigências absurdas e desgastantes aos programas!

Mas não me parece que essa seja a única saída. A área que secretou grande experiência na realização de pesquisas qualitativas nas últimas décadas deveria mobilizar essa expertise para inventar novas formas, novas metodologias e novos critérios de avaliação que fossem mais justos e mais centrados no Programa do que no pesquisador.

A avaliação do Programa não precisa depender exclusivamente, nem principalmente, dos dados coletados pelo "sistema" a cada início de ano. Uma possibilidade seria, por exemplo, utilizar o quadriênio para fazer avaliações qualitativas dos programas. O conceito do Programa poderia resultar da síntese desses dois processos.

Sei que não é fácil operacionalizar uma proposta desse tipo, mas 
penso que é uma das únicas formas de superarmos a suposta avaliação da qualidade dos programas baseada em aspectos formais - tempo de titulação, número de alunos por orientador, número de projetos por docente, distribuição das disciplinas entre os docentes, proposta do Programa etc. - ou em dados "objetivos" coletados pelo sistema relativos à produção docente e discente. Mais do que isso, é uma das únicas formas de avaliarmos os programas levando em conta, e incentivando, uma ação coletiva baseada nas diversas sensibilidades, qualidades e competências de seus alunos e professores.

Mas, para isso, é preciso que distingamos qualidade da formação ofertada no Programa, conforme já salientamos antes, da avaliação dos resultados da pesquisa realizada e objetivada nas publicações dos alunos e dos professores. Mais do que isso, é preciso relativizar a própria produção bibliográfica como carro-chefe de toda a avaliação da qualidade dos programas, possibilitando-nos superar e, quem sabe, enfrentar uma dicotomia que vem ganhando cada vez mais adeptos na área: a do produtivismo x produção qualificada. Tal questão será objeto de nossa reflexão a seguir.

f) Entre o produtivismo e a produção qualificada: há, hoje, no campo da Pós-graduação em Educação, um crescente grupo de professores e, eventualmente, de alunos que questiona a avaliação, e o faz afirmando que essa tem levado muito mais a um produtivismo acadêmico do que ao aumento da qualificação da produção na área.

É importante destacar que, para vários pesquisadores, a ideia de produtivismo acadêmico não se restringe aos aspectos relacionados a um possível aumento exagerado da produção científica. Essa ideia abarca desde a formação do pesquisador, passando pela elaboração do projeto, pela realização da pesquisa, pela publicação de seus resultados, até chegar à avaliação do conjunto do processo. Assim, a ideia de produtivismo, em que pese a sua mobilização muito restritiva em boa parte das críticas à avaliação da pós-graduação, tem, originalmente, alcance mais lato e abrangente.

A respeito do produtivismo como um possível aumento exagerado da produção, retomo aqui minha posição já tornada pública em outro 
momento: o expressivo aumento da produção e da publicação de conhecimentos acadêmicos sobre Educação observado nos últimos anos se relaciona ao número de pesquisadores e de estudantes e ao crescimento da área. Nesse caso, não podemos falar em produtivismo. Os dados da CAPES demonstram que, em média, cada pesquisador da pós-graduação publica não mais do que um artigo ou capítulo de livro por ano.

No entanto, reconhecer que não se pode falar em produtivismo não responde ao problema central posto: o de que o funcionamento do conjunto do sistema, aí incluída a CAPES, o CNPq, as FAPs e as demais agências de financiamento e de regulação da pesquisa e da pósgraduação, tem levado à precarização das condições de trabalho e de pesquisa e à diminuição da qualidade da produção. Que houve uma intensificação do trabalho, não resta dúvida. Agora, em que medida isso tem significado a precarização e a avaliação de que a produção é, hoje, menos qualificada do que a anterior prescinde de maior aprofundamento por parte da área.

Penso que um de nossos grandes problemas é, na verdade, estabelecer o que é produção de qualidade na pós-graduação. No campo acadêmico, há certo consenso sobre essa questão que precisamos considerar: produção mais qualificada é aquela que segue os critérios de consagração e de qualidade considerados de maior excelência pelas respectivas áreas ou, no pior dos casos, pelas áreas melhor posicionadas no conjunto do sistema!

A esse respeito, nós, ao utilizarmos o Qualis CAPES como nosso principal critério de qualidade, estamos longe do detalhamento utilizado por várias outras áreas do sistema. No entanto, é preciso considerar que, conforme vimos argumentando, na área de Educação, é preciso que sejamos mais abrangentes. Aqui, a qualidade do conjunto da produção não se mede apenas e tão somente pelos critérios acadêmicos stricto sensu.

Sabe-se que a atual Comissão de Avaliação da Área de Educação na CAPES, em conjunto com os coordenadores de programas, a exemplo do que fez o Comitê de Assessoramento da Educação no CNPq, está propondo que haja uma delimitação do número de publicações a serem consideradas no quadriênio. Isto, certamente, é sinal de que há incentivo 
maior à qualidade do que à quantidade. No entanto, penso que isso é importante, mas não basta. É preciso reestabelecer o rediscutir os critérios de excelência e de qualidade da produção.

O reiterado exemplo dos livros didáticos é, disso, emblemático. Para serem de qualidade, é preciso pesquisa, estudo e refinamento analítico e de organização, para dizer pouco. Produzi-los é, quase sempre, muito mais difícil do que produzir um artigo ou um livro acadêmico. No entanto, segundo as regras de consagração acadêmica, eles não têm importância alguma. O argumento de que são considerados importantes para a avaliação de outras dimensões dos programas, como o impacto social, não é justificativa para desconsiderá-los como produção acadêmica de qualidade no campo da Educação.

Sabemos que a apropriação, pela educação, dos critérios de consagração próprios do campo acadêmico-científico foi, ou tem sido, estratégia fundamental de seu fortalecimento dentro desse campo. No entanto, não podemos fazer isso à custa de se desconsiderar boa parte daquilo que é produzido nos programas.

De outra parte, não podemos nos esquecer de que alguns critérios de excelência acadêmica, como a supervalorização dos artigos, podem ter, em nossa área, efeito perverso, ao desestimular gêneros textuais de fundamental importância, como livros e ensaios, e mesmo ao constranger a pesquisa, que passa a ser organizada em função desses critérios.

Enfim, aqui, como nas outras dimensões, não há saída fácil. Mas o pior dos mundos será se desistirmos da criação de condições para que nossas pesquisas, assim como a exposição de seus resultados, sejam realizadas de forma criativa e prazerosa e que façam avançar o conhecimento em nossa área.

g) A internacionalização que nos interessa: o assunto é importante, porque a internacionalização é um dos principais vetores das políticas contemporâneas de C\&TI desenvolvidas no Brasil nas últimas décadas. Apesar de não ser uma experiência nova para os pesquisadores brasileiros, a intensidade e o enquadramento propostos para a internacionalização nas atuais políticas não conhecem antecedentes em nossa história acadêmico-científica. 
A minha intenção é problematizar os programas de internacionalização em curso no país e apontar alguns elementos da internacionalização que podem favorecer o fortalecimento acadêmico-científico das Humanidades ou, mais especificamente, da Educação e aumentar seu impacto na produção e na divulgação do conhecimento na área.

A perspectiva internacional ou global é, na maioria das vezes, a perspectiva local dos que dominam. O local é sempre polissêmico. $\mathrm{O}$ local é aqui onde eu me encontro; é lá onde o outro se encontra; é acolá, onde nos encontramos. O local é o espaço do encontro, mesmo que este seja um grande desencontro.

É da política que se fala quando dizemos da internacionalização que não nos interessa. Nós não queremos uma internacionalização em que sejamos o local dos outros, enquanto o internacional é o local do colonizador (de ontem ou de hoje). Não queremos uma internacionalização quando o referente do outro nos torna eternos aprendizes, e, ele, o nosso educador. Não queremos uma internacionalização em que as Humanidades não tenham lugar e que se esqueça de que o que mais interessa ao estrangeiro é o encontro, e não o re-conhecimento matemático, físico, químico ou médico. Por isso, não queremos uma internacionalização que reconheça um único conhecimento e uma única forma de conhecer. A internacionalização não pode ser mais uma forma de ocidentalização do mundo e de seus modos de ex-posição. Do mesmo modo, não queremos uma internacionalização que nos aliene do nosso local, nem do local do outro. Por isso, a internacionalização não pode ser um comércio.

Queremos uma internacionalização em que o encontro com o outro, no e com o local do outro, seja oportunidade de revisão do nosso local. Que seja possibilidade de estranhamento e de reconhecimento, pois, como dirá Chico Buarque, "quem jamais esquece não pode reconhecer". Mas que seja também possibilidade de reconhecer o outro do nosso local. Sim, queremos uma internacionalização que seja multicêntrica ou, se preferirmos, multilocal. Nossa internacionalização tem que aspirar fortalecer os saberes e as epistemologias locais (e não a sua destruição). Uma internacionalização assim será inovadora, mas virá de mãos dadas com a tradição. O viajante aprende com o outro, aprende do outro, 
apreende o outro. Mas também desloca os sentidos, costura e sutura para produzir outros sentidos. Inova, renova.

A tradição que queremos atualiza o melhor da tradição crítica das Ciências Humanas e Sociais. E o que funda as Humanidades é o encontro (e os desencontros) com o outro. Por isso, a vocação internacionalista está no coração das Humanidades. O encontro com o outro local ou com o local do outro é parte fundamental da política fundada no espaço público e na alteridade, mas também das políticas públicas de reconhecimento de direitos, de invenção de direitos e, logo, da própria alteridade e do espaço público.

Por isso, sem as Humanidades, não há política de internacionalização que se sustente, a não ser aquela que queira nos alienar no e do local do outro. Mas o desejo que nos empurra nessa direção não é o mesmo que nos mobiliza para nos alienar dos outros de nosso próprio local, tornando a internacionalização uma perigosa ferramenta de estreito nacionalismo e da xenofobia?

Publicar, expor o nosso local no local do outro pode ser tanto uma forma de alienação quanto de crítica. Enquanto nossos parceiros não se reconhecerem como local e desejarem a internacionalização como encontros de locais, a nossa internacionalização será pouco mais do que a alienação de nossos conhecimentos e das epistemologias locais. Tanto mais se essa alienação for financeira também.

Em termos mais operacionais, nossa internacionalização somente será sustentável e efetiva, a médio e longo prazos, se for baseada na internacionalização da pesquisa e da formação, e não apenas da publicação (ou da divulgação, se preferirem). Também é fundamental, a esse respeito, que nossa internacionalização se dirija a todos os locais do mundo, não ficando restrita, pela língua ou por conveniência, a alguns poucos países. Levando em conta os critérios acadêmicos, sabemos que em muitas áreas é muito melhor internacionalizar-se com a América Latina e, certamente, com países árabes e asiáticos do que com os EUA e a Europa. Nesse sentido, urge que a área, se possível, numa conjunção de esforços entre a CAPES, o CNPq e as FAPs, estabeleça um Plano Estratégico de Internacionalização da Pesquisa em Educação. 
Em tal Plano deveria figurar, com destaque, as estratégias a serem desenvolvidas para a atração de alunos e pesquisadores para trabalharem conosco no Brasil. Mas isso implica também a construção, em nossos programas e faculdades de Educação, de estruturas que favoreçam a internacionalização da pesquisa. Tal como é hoje, a internacionalização implica num conjunto de custos pessoais para os professores que faz com que poucos estejam dispostos ou disponíveis para tal atividade.

Finalmente, no que se refere especificamente à avaliação, esta deveria incidir muito mais sobre os esforços e os processos de internacionalização da pesquisa e da formação dos alunos e dos professores dos programas do que sobre os produtos dessa internacionalização, sobretudo no que se refere aos artigos e livros publicados fora do país. Do mesmo modo, tal avaliação deveria levar em conta as desigualdades de acesso às oportunidades de internacionalização considerando, por exemplo, a atuação das agências nacionais e estaduais de fomento.

Se queremos que a internacionalização de nossa pesquisa seja, de fato, sustentável, e que a avaliação contribua para alavancá-la, e não apenas para se constatar o "estado da questão" em cada Programa, é preciso, hoje, apontar horizontes alargados de ação nesse sentido. Esse é, parece-me, o nosso principal desafio atualmente.

h) Impacto social dos programas de pós-graduação: a introdução de um critério que avaliasse o impacto social dos programas de pósgraduação sempre foi, não necessariamente com esse nome, uma reivindicação da área de Educação e de algumas outras áreas do sistema, notadamente aquelas que mantêm relação direta com as políticas públicas, como é o caso da Saúde, por exemplo. É curioso, portanto, notar que, quando o CTC da CAPES não apenas autorizou a inclusão do critério, mas também o impôs como regra para todas as áreas, a área da Educação pouco se preocupou com sua discussão e seu detalhamento.

Lembro-me de que estávamos lá pelo ano de 2004 ou 2005, o professor Robert Verhine era Coordenador da Área e eu estava na Coordenação do PPGE-UFMG. Numa reunião do Fórum de Coordenadores, em Caxambu, dividimos os grupos para discutirmos os critérios da avaliação, e pouquíssimos fomos os que escolhemos discutir o critério do impacto 
social, que seria utilizado pela primeira vez naquele triênio. Saímos da reunião com muito pouco detalhamento, e foi aberta a oportunidade para que os programas se manifestassem posteriormente. Nosso Programa fez uma longa e rica discussão e escreveu um detalhado documento sobre o assunto, indicando quesitos que poderiam subsidiar a Comissão de Área. Posteriormente, o professor Verhine me disse que, também nessa oportunidade, os programas praticamente não se manifestaram sobre a questão.

De lá para cá, 12 anos e três avaliações depois, não houve aprofundamento desse tema, e o que ocorreu é que o critério de "Impacto Social dos Programas", embora reivindicado pela área, tem sido elemento inócuo nas avaliações realizadas. Há que se perguntar, em alguma ocasião, que motivos levaram a área e, mesmo, as Comissões de Avaliação a não se comprometerem com a questão. Seria o fato de, na área, termos muitos programas de instituições privadas e confessionais às quais o critério talvez penalizasse? Seria o fato de que o modelo de avaliação da CAPES, no seu conjunto, privilegie programas pequenos e médios, e o impacto social seja elemento importante sobretudo para os programas grandes? Se sim, por que mesmo esses não se mobilizaram?

Não cabendo aqui buscar resposta para essas questões e, talvez, para outras mais pertinentes, gostaria de sugerir uma resposta mais geral ao problema e, em seguida, buscar pensar possíveis elementos para avançarmos na discussão sobre os impactos sociais dos programas de pós-graduação em Educação.

Uma razão mais geral pela qual nossa área não tenha se debruçado mais detidamente sobre a temática do impacto social talvez esteja no fato, já tratado em outro momento, de que, no jogo de forças que regula as relações de poder dentro do sistema de pós-graduação, tenhamos optado pela maior adesão aos critérios mais estritamente acadêmicos como forma de nos colocarmos em melhor posição dentro do conjunto das áreas. Num momento em que éramos continuamente cobrados, interna e externamente à área, pela nossa baixa adesão aos padrões de excelência acadêmica, utilizar o critério de impacto social poderia parecer um enfraquecimento da área, já que ele poderia ser visto como vago, 
indefinido e menos acadêmico para discriminar os programas uns dos outros. Nessa perspectiva, pode ter parecido às Comissões de Avaliação ser mais importante tornar o critério inócuo do que enfrentar a espinhosa discussão que ele impunha.

Analisado globalmente, o impacto social de um programa somente pode ser avaliado pelo conjunto de suas ações. É por isso, inclusive, que ele pode ser um critério importante para matizar o modelo de avaliação até hoje utilizado, que privilegia pequenos e médios programas: um programa grande teria, assim, quase certamente, impacto social maior do que aqueles. Mas, sem deixar de considerar esse aspecto, é preciso especificar aquilo que estamos considerando na avaliação do impacto social.

Uma dificuldade para avaliarmos o impacto social dos programas é que, no modelo atual, somente podemos fazê-lo indiretamente. Ou seja, não é possível termos indicadores diretos do impacto dos programas, pois isso demandaria o estabelecimento, a priori, dos indicadores que seriam examinados e, mais do que isso, a utilização de metodologias que permitissem aquilatar de forma mais precisa qual foi, de fato, o impacto da ação deste ou daquele Programa de Pós-graduação na melhoria daqueles indicadores numa determinada realidade.

No entanto, sejam quais forem as razões da não discussão, e para a não especificação e/ou utilização do critério, parece-me que é justamente ele que nos ajudaria a estabelecer uma clara ponte com a resposta a uma outra questão com a qual temos sido continuamente fustigados: qual o impacto da Pós-graduação em Educação na qualidade da educação básica no país? Em que pese a pertinência da questão, ela tem sido mobilizada constantemente mais para desautorizar a participação da área da Educação em certas iniciativas e programas de financiamento à pesquisa do que, verdadeiramente, para aquilatar a nossa contribuição. Mas, nem por isso, deixa de ser uma questão pertinente.

Se a relação com a educação básica e com as políticas de educação poderiam ser bons caminhos para pensarmos o impacto social dos programas, inclusive como induz o Plano Nacional de Pós-graduação para todas as áreas, nem todo o conteúdo e toda forma dessa relação 
deveriam ser tomados como importante na avaliação desse critério. Isso porque muito daquilo que consideramos, globalmente, como impacto social dos programas já é avaliado por outros critérios.

Uma das dimensões positivas da avaliação do impacto social é, pois, o fato de ela nos obrigar a olhar e a avaliar aquilo que até hoje tem ocupado muito de nosso tempo e energia, e que tem sido pouco considerado: a relação com as políticas públicas de educação e as ações e os produtos que a acompanham, operacionalizam-na e objetivam-na. Nesse sentido, quais seriam tais ações e tais produtos?

As publicações acadêmicas - livros, capítulos de livros, artigos e anais em eventos - não deveriam entrar aqui. Do mesmo modo, as dissertações e teses deveriam ser afastadas. Além destes, todos os trabalhos técnicos referentes à dimensão especificamente acadêmica dos programas (participação em bancas, conselhos editoriais, produção de pareceres, atuação em comissões das agências de fomento e de avaliação, ações de gestão universitária etc.) ficariam de fora.

O que, então, entraria? Em primeiro lugar, todas as ações junto à educação básica, bem como os seus respectivos produtos, desenvolvidos pelos docentes e alunos: organização e realização de cursos de formação; produção de material didático para a educação básica; editoração de revistas de divulgação; produção de vídeos, filmes, programas de rádio e páginas na internet dirigidos à escola básica; participação em comissões de assessoria e de consultoria a instituições públicas e privadas relacionadas à educação básica.

Além desses, uma dimensão importante a ser observada aqui são aquelas ações e os produtos desenvolvidos pelos docentes que visam divulgar as pesquisas e opiniões para o público não especializado ou não diretamente relacionado à educação básica: programas de rádio e TV; vídeos, filmes e páginas na internet; manutenção de blogs e de páginas nas redes sociais; textos publicados em jornais e revistas não especializados; entrevistas concedidas aos meios de comunicação, convencionais ou não.

Um aspecto importante a ser avaliado pela área é como distinguir, no processo de avaliação, aquelas ações que são desenvolvidas dentro de 
projetos que envolvem o pagamento de bolsas e/ou pró-labore para os docentes e/ou para os discentes. Nesse caso, uma possibilidade seria a de pontuá-los de forma diferenciada daqueles projetos de extensão e de ensino oferecidos de forma gratuita para as redes e/ou para os docentes da escola básica e/ou para o público não especializado.

Os indicadores a serem mobilizados poderiam ser tanto de ordem formal quanto quantitativa e qualitativa. De ordem formal, parece que um dos indicadores seria a existência ou não de convênios e/ou acordos assinados entre os docentes e/ou grupos de pesquisa do Programa com os parceiros da ação, sejam estes instituições públicas, privadas ou movimentos sociais. Outro seria o registro dessas ações nos sistemas e órgãos competentes das instituições-sede dos programas. Do ponto de vista quantitativo, um indicador relevante é quantas são as pessoas alcançadas direta e indiretamente pelas ações desenvolvidas, carga horária etc. Do ponto de vista qualitativo, uma possibilidade seria a de analisar a relação entre as ações desenvolvidas pelos docentes e discentes nessas ações de impacto social e suas linhas e projetos de pesquisa.

Finalmente, para não gerar dúvida nas Comissões de Avaliação, os próprios programas deveriam ser os responsáveis por classificarem suas ações e seus produtos que deveriam ser utilizados para avaliar seu impacto social. Nesse caso, tais ações e produtos não deveriam ser utilizados para a avaliação das demais dimensões do Programa, a não ser subsidiariamente. Independente do caminho que venha a ser tomado, o fundamental é que discutamos amplamente a questão e que incorporemos o critério do impacto social do Programa como elemento importante da avaliação.

À guisa de conclusão: como superar a avaliação como política?²

Durante a $12^{\mathrm{a}}$ Reunião Científica Regional Sudeste da ANPED, tivemos uma mesa redonda sobre a avaliação da pós-graduação da qual

2 No final de 2015, a CAPES instituiu um conjunto de Grupos de Trabalho para estudar a pósgraduação no país e propor novas formas de avaliá-la. Parece que a intenção não é de fazer apenas reformas cosméticas no sistema e na avaliação, como vimos até hoje. 
participaram a professora Patrícia Corsino (UFRJ), o professor Marcos Francisco Martins (UFSCar) e eu. Nela, foram externadas preocupações, diagnósticos e propostas aceca da Pós-graduação em Educação no país. A maior preocupação explicitada, e que envolvia muitos dos coordenadores de programas de pós-graduação que lá estavam, é relativa ao fato de estarmos no final do quadriênio que será avaliado e, até hoje, não temos estabelecidos e publicados os critérios que serão mobilizados. Isso gera insegurança e a sensação de que, de forma muito injusta, as regras podem ser estabelecidas ou mudadas após o término do jogo!

Essa discussão sobre os critérios faz parte, por sua vez, de um diagnóstico de que, hoje, não temos uma política de pós-graduação e de pesquisa para a área, o que sobreleva, de modo artificial, a importância da avaliação realizada pela CAPES e a transforma, de fato, em política. Ou seja, de forma pervertida e invertida, a avaliação, que deveria ser uma das dimensões e um dos momentos da política, converte-se na única política da CAPES para a área de Educação.

O problema é que, na ausência de uma política, a pós-graduação e a pesquisa na área de Educação ficam sujeitas, única e exclusivamente, à ação dos órgãos de fomento e controle ou, o que não é nada animador, às ações dos pesquisadores e das instituições singulares espalhadas pelo território nacional. Desse modo, não há definição de prioridades para a produção de conhecimento, para a formação de novos pesquisadores e de recursos humanos para a Educação e, evidentemente, para o investimento público na área. Nessa dinâmica, não apenas é impossível planejar e, portanto, avaliar consistentemente o sistema, mas também são criadas as condições para a manutenção e o aprofundamento das desigualdades inter e intrarregional e, mesmo, interinstitucional.

Nesse sentido, uma das perspectivas que foi ressaltada é que se torna urgente a elaboração de uma política de pesquisa e de pós-graduação para a área de Educação. Esta seria a única forma de se evitar que a avaliação continue sendo a única política, e também de responder de forma consistente aos grandes desafios postos pela sociedade brasileira. Seria uma forma, ainda, de resgatar nossa capacidade de planejar e, portanto, de definir prioridades de produção de conhecimentos, de formação 
e de investimento. Tal política incorporaria a avaliação como um de seus momentos, oferecendo às Comissões de Área e aos Comitês de Assessoramento das agências de fomento parâmetros coletivamente acordados.

Sabemos que a elaboração de tal política depende da vontade dos diversos coletivos que atuam na pesquisa e na Pós-graduação em Educação e de interlocução com as agências de fomento e de regulação, com os gestores públicos e com as organizações dos professores da escola básica. A tarefa não é fácil, mas é a única saída para o desconforto dos sujeitos que atuam na área e para a crescente disfuncionalidade do sistema, inclusive no que se refere às grandes demandas postas, hoje, pela educação básica brasileira. 